\title{
Effectiveness of Laser Therapy (AlGaInP) on Cicatrization of Experimental Cutaneous Wound in Rats
}

\author{
Renata dos Santos Vasconcelos ${ }^{1}$, Renata Prado Vasconcelos ${ }^{2}$, \\ Luana Torres Monteiro Melo ${ }^{3}$, Carolina Araújo Castro ${ }^{4}$, \\ Adriana Rolim Campos', Ana Paula Vasconcellos Abdon 4 \\ ${ }^{1}$ Department of Medical Sciences, Federal University of Ceara (UFC), Fortaleza, Brazil \\ ${ }^{2}$ Department of Physiology, State University of Ceara (UECE), Fortaleza, Brazil \\ ${ }^{3}$ Department of Biotechnology, State University of Ceara (UECE), Fortaleza, Brazil \\ ${ }^{4}$ Department of Health Sciences, University of Fortaleza (UNIFOR), Fortaleza, Brazil \\ Email: renatavasconcelos23@gmail.com, renatiets@hotmail.com, luanatmelo@hotmail.com, \\ carolinaaraujo1987@hotmail.com, adrirolim@unifor.br, paulaabdon@unifor.br
}

Received 14 January 2014; revised 13 February 2014; accepted 12 March 2014

Copyright (C) 2014 by authors and Scientific Research Publishing Inc.

This work is licensed under the Creative Commons Attribution International License (CC BY). http://creativecommons.org/licenses/by/4.0/

(c) (i) Open Access

\section{Abstract}

The use of laser therapy is one of the most effective tools in the prevention and treatment of skin ulcers. It is an effective treatment choice because it potentiates the trophic regenerative, anti inflammatory, and painkiller effects. This study aimed to assess the effectiveness of low level laser therapy in treating induced cutaneous ulcers in rats. An experimental study using 12 female Wistar rats (Rattus novergicus), weighing between 150 and $250 \mathrm{~g}$, from the room of animal husbandry at the Center of Health Sciences of UNIFOR. Rats underwent surgery to induce cutaneous ulcer. Subsequently, the animals were divided into two randomized groups: 1) Control group; and 2) Experimental group. They received nine applications of AlGaInP laser treatment (power of $30 \mathrm{~mW}$ ) with an intensity of $4 \mathrm{~J} / \mathrm{cm}^{2}$, using the scan method, for 15 seconds over the entire ulcer. The cicatrization process was evaluated from the $1^{\text {st }}$ to $1^{\text {th }}$ postoperative $(\mathrm{PO})$ day, but on alternate days. The results showed that animals treated with laser had less area of cutaneous wound than the control group from the $7^{\text {th }}$ until the $17^{\text {th }}$ postoperative day, highlighting the $7^{\text {th }}$ and the $9^{\text {th }} \mathrm{PO}$ with a significant reduction in wound area of $28.8 \%(p=0.00)$ and $23,5 \%(p=0.01)$, respectively. Treatment with the AlGaInP laser was effective in the repair of cutaneous wound when compared to the control group-particularly on the $7^{\text {th }}$ postoperative day.

\section{Keywords}

Laser Therapy, Rats, Wound Healing, Regeneration

How to cite this paper: Vasconcelos, R.S., et al. (2014) Effectiveness of Laser Therapy (AIGalnP) on Cicatrization of Experimental Cutaneous Wound in Rats. International Journal of Clinical Medicine, 5, 525-530. 


\section{Introduction}

Skin wounds are tissue disorders that affect millions of people around the world and have major physical and emotional consequences which can make a person unable to move spontaneously [1].

Skin ulcers are characterized by integumentary loss, which can be limited or irregular. Among the most common types of ulcers are arterial vascular and venous ulcers. These ulcers are caused by pressure as well as peripheral neurological deficit, and may evolve over time [2].

The process of skin wound healing involves a series of factors that aim to restore the normal function of the affected region [3]. This process is divided into three phases: inflammation, proliferation and remodeling of the extracellular matrix [4].

The therapies used on skin ulcers aim to prevent and treat these wounds. The physiotherapy can contribute to recovery from these injuries by reducing the healing period and facilitating the return to functional activities more quickly.

Among the several existing physiotherapeutic treatments is the use of the low level laser (Light Amplification by Stimulated Emission of Radiation), which stimulates the healing process, and is considered more effective than other modalities used in treatment clinics [5].

Laser therapy is one of the most used techniques in the treatment of skin ulcer because it enhances the trophicregenerative, anti-inflammatory and analgesic effects [6]. In addition, tissue regeneration is highlighted [7].

Some studies, correlated with the irradiation of low-level laser in the production of collagen, have shown very positive results [8]. They indicate an increase in the production of fibroblasts in induced and irradiated skin wounds, which supports the healing process [9]. Currently, a new type of laser is being used in the domestic market: the AlGaInP (Aluminium, Gallium, Indium, Phosphorus) laser, which has a wavelength similar to the HeNe (Helium Neon), but that needs a shorter time of irradiation because it presents a higher average power [10].

This study aimed to analyze the effectiveness of low level laser therapy on skin wound induced in rats and verify the application parameters in skin wound, since there are still some controversies regarding its standardization.

\section{Method}

\subsection{Design}

An experimental quantitative study was conducted in Laboratories $\mathrm{H}-08$ and $\mathrm{H}-10$ at the University of Fortaleza (UNIFOR).

\subsection{Participants, Therapists, Centers}

We used 12 female Wistar rats (Rattus novergicus), weighing between 150 and $250 \mathrm{~g}$, from the room of animal husbandry from the Center for Health Sciences at UNIFOR. The animals were housed in acclimatized cages containing until six animals, with natural day/night cycles, and were provided with water and ad libitum feeding, except during the period of intervention.

This study followed the ethical principles of animal research, adhering to the rules of the National Council for the Control of Animal Experimentation (CONCEA) and the incorporation of the "3Rs" (reduction, replacement, refinement), which is an experimental practice that leads to reducing the number of animals used, their replacements (when possible or relevant) and the refinement of the techniques used. It was submitted to the Ethics Committee on the Use of Animals (CEUA) at UNIFOR, with legal opinion No. 010/2011.

\subsection{Intervention}

On the day of surgery, after a fasting period of 8 hours, the animals were weighed and anesthetized intraperitoneally (i.p) with with ketamine $(70 \mathrm{mg} / \mathrm{kg})$ and xylazine $(10 \mathrm{mg} / \mathrm{kg})$ in distilled water, with a dosage of 0.1 $\mathrm{ml} / 30 \mathrm{~g}$ of the animal weight.

After the anesthetic procedure, each animal was placed on a surgical board in ventral decubitus position and immobilized by adhesive tape. Then, trichotomy by manual traction of part of the dorsal thoracic region was applied, and povidone iodine $1 \%$ was used to provide asepsis.

After the hair was removed, the same surgical technique was standardized for the animals from all groups. 
Sterilized surgical drapes were placed on the animal and the skin to be excised was marked with a demographic pen and cast plastic molding, to define an area of $2 \times 2 \mathrm{~cm}^{2}$. The skin was incised using a No. 21 scalpel blade, removing the layer of the dermis and epidermis up to the exposure of the muscle fascia. Hemostasis was achieved by digital compression with gauze.

After the described surgical procedure, the animals were randomized into two groups ( $n=6 /$ group) according to the type of treatment:

1) Control group: used only saline in the wound;

2) Experimental group: used the AlGaInP laser, Laserpulse Ibramed ${ }^{\circledR}$ model, with visible beam, in pulsatile mode, $30 \mathrm{~mW}$ power, with a $660 \mathrm{~nm}$ wavelength pen, an intensity of $4 \mathrm{~J} / \mathrm{cm}^{2}$, and using the scan method for 15 seconds throughout the length of the wound.

The control and the experimental groups were submitted to the treatment on the following postoperative days (PO): $1^{\text {st }}, 5^{\text {th }}, 3^{\text {rd }}, 7^{\text {th }}, 9^{\text {th }}, 12^{\text {th }}, 15^{\text {th }}, 17^{\text {th }}$ and $19^{\text {th }}$. After inducing skin wound, the animals were assessed at the same times.

The wound areas were analyzed and the horizontal and vertical diameters were determined using calipers (Digital Caliper within $300 \mathrm{~mm}$ ), with the calculation of the area obtained using the equation [11]. A = R x r, in which $A$ represents the area, $R$ the larger radius, and $r$ the smaller radius of the wound.

The area of lesion was calculated using the equation [12]. $\Delta \mathrm{A}=100 \times(\mathrm{Wo}-\mathrm{Wi}) / \mathrm{Wo}$, in which $\mathrm{Wo}=$ initial wound area; $W i$ = final wound area.

\subsection{Outcome Measures}

Primary outcome: The aid of the therapy with the AlGaInP laser in reducing skin wound in the treated group as compared to the control group.

Secondary outcome: Period of greater neovascularization and re-epithelization and the consequent increased speed in the healing process of the skin wound.

\subsection{Data Analysis}

After data collection, the results were presented through the average \pm standard error, expressed in the form of figure and table. The $t$ test for independent samples was conducted, following the normality test by KomogorovSmirnov (KS), and only the analyses that presented a significance level of $5 \%(\mathrm{p} \leq 0.05)$, by the Statistical Package for the Social Sciences (SPSS) program version 17.0, were considered statistically different.

\section{Results}

Results showed that the animals treated with laser presented a smaller area of skin wound than the control group from the $7^{\text {th }}$ to the $17^{\text {th }}$ postoperative days (Figure 1). In addition, it was observed that the group treated with laser showed better healing when compared to the control group, with significant reduction of the wound area of $28.8 \%(\mathrm{p}=0.00)$ and $23.5 \%(\mathrm{p}=0.01)$ on the $7^{\text {th }}$ and $9^{\text {th }}$ postoperative days, respectively (Table 1$)$.

\section{Discussion}

As highlighted by epidemiological data, skin wound is the most common result of external physical forces [1]. Furthermore, the residual repair is a highly complex mechanism that involves local and systemic factors that can compromise wound healing [3].

The healing process of wounds may benefit from factors such as the nutrition of tissues, cell proliferation and inflammation control [13]. Among the therapeutic resources that promote the healing process, electrotherapy is one of the most used techniques in the treatment of skin wound because the application of the AlGaInP low level laser produces trophic-regenerative, anti-inflammatory and analgesic effects [13].

This type of laser produces light with a wavelength between 635 and $670 \mathrm{~nm}$, occuring within the visible red color range of the light spectrum, with potential variation of 1 to $30 \mathrm{Mw}$, which gives it a biostimulant action [14].

The results of this study showed that AlGaInP laser therapy accelerated the healing process, possibly because it assists tissue regeneration. This finding is in agreement with previous study with low-level laser that used a wavelength of $670 \mathrm{~nm}$ and a dose of $30 \mathrm{~J} / \mathrm{cm}^{2}$, which contributed to the repair of the dermis and epidermis, and 


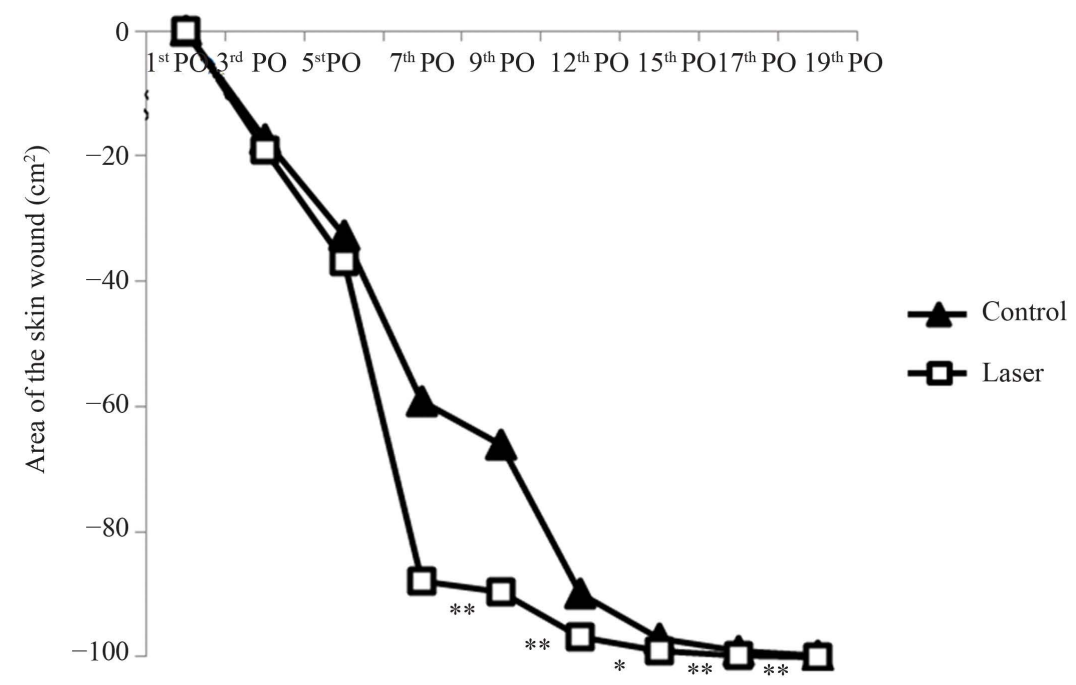

Figure 1. Analysis of the AlGaInP laser effect on the healing process of the skin wound in rats. The healing process was measured through the area of the skin wound in $\mathrm{cm}^{2}$ through the \pm standard error average. The ordinate axis: averages of wound areas. Abscissas axis: postoperative day. There was a statistically significant difference between groups ( ${ }^{*} \mathrm{p}<0.05$ and $\left.{ }^{* *} \mathrm{p}<0.01\right)$.

Table 1. Analysis of the evolution of the healing process of the skin wound in animals treated with the AlGaInP laser and the control.

\begin{tabular}{|c|c|c|c|c|}
\hline \multirow{2}{*}{$\begin{array}{l}\text { Postoperative period. } \\
\text { (PO) }\end{array}$} & \multicolumn{3}{|c|}{ Area of skin wound } & \multirow{2}{*}{$\mathrm{P}$} \\
\hline & Control & Experimental & Difference between groups & \\
\hline $3^{\text {rd }} \mathrm{PO}$ & $17.2 \pm 7.41$ & $19.0 \pm 8.72$ & 1.8 & 0.88 \\
\hline $5^{\text {th }} \mathrm{PO}$ & $32.5 \pm 5.00$ & $36.7 \pm 6.86$ & 4.2 & 0.63 \\
\hline $7^{\text {th }} \mathrm{PO}$ & $59.1 \pm 6.00$ & $87.9 \pm 3.17$ & 28.8 & 0.00 \\
\hline $9^{\text {th }} \mathrm{PO}$ & $66.1 \pm 6.39$ & $89.6 \pm 2.53$ & 23.5 & 0.01 \\
\hline $12^{\text {th }} \mathrm{PO}$ & $89.9 \pm 2.49$ & $98.7 \pm 0.80$ & 6.8 & 0.03 \\
\hline $15^{\text {th }} \mathrm{PO}$ & $96.9 \pm 0.39$ & $99.0 \pm 0.48$ & 2.1 & 0.01 \\
\hline $17^{\text {th }} \mathrm{PO}$ & $98.9 \pm 0.18$ & $99.8 \pm 0.14$ & 0.9 & 0.00 \\
\hline $19^{\text {th }} \mathrm{PO}$ & $99.8 \pm 0.18$ & $99.9 \pm 0.09$ & 0.1 & 0.65 \\
\hline
\end{tabular}

potentiated the healing of induced wounds on the backs of mice [15].

This research showed that the use of the AlGaInP laser therapy was effective in reducing the wound earlier, as this type of laser increases the secretion of growth factors (FGF) and cell replication, thereby increasing cell proliferation. It also reduces inflammation and promotes neovascularization that, regardless of the dose used, may be the determining factor in the tissue repair [5].

In another study, the therapy using the $785 \mathrm{~nm}$ AlGaInP laser, with a dose of $2.7 \mathrm{~J} / \mathrm{cm}^{2}$, showed positive effects in reducing the inflammatory infiltrate and in accelerating the healing process because the laser increased fibroblast proliferation, thus creating conditions for the alignment and organization of the muscle fiber [16].

In this study, we observed a significant reduction in the diameter of the wound areas in the group treated with laser, primarily on the $7^{\text {th }}$ postoperative day, when compared to the control group. This improvement in the healing process may be attributed to the decreased inflammatory infiltrate and the early re-epithelization that usually occurs at this stage of tissue repair [17].

The extensive reduction of the ulcers on the $7^{\text {th }}$ postoperative day is linked to the occurrence of hyperplasia and epidemic hypertrophy as well as an increase in neovascularization. These results are associated with fibrop- 
lasia in the presence of fibroblasts and type III collagen, which aid in the healing process [18] [19].

All the effects achieved with the use of the AlGaInP laser may be related to its potent biostimulant action and because it has a wavelength that requires less irradiation to produce desirable effects. Recent studies show that this new type of laser may be effective when used at a dose of $4 \mathrm{~J} / \mathrm{cm}^{2}$ in the scan mode, on third degree burns [20].

The scan method with a dose of $4 \mathrm{~J} / \mathrm{cm}^{2}$, when used on rats that had received burns, proves more effective because it presents a faster healing process than the group that used the laser with the punctual method, showing the positive effects of laser irradiation [21].

In this study, we used the AlGaInP laser at a dose of $4 \mathrm{~J} / \mathrm{cm}^{2}$ in the scan mode for a period of 15 seconds. The authors report that the dose used in this research is more efficient in increasing the number of fibroblasts, achieving greater vascular proliferation, and in re-epithelization. Laser therapy with the use of $4 \mathrm{~J} / \mathrm{cm}^{2}$ is more efficient than with the use of $8 \mathrm{~J} / \mathrm{cm}^{2}$ because a smaller dose helps in reducing the diameter of the wound, edema and the number of inflammatory cells [20] [21].

Despite the positive results of the research, more studies are still needed with this type of laser to find more evidence of the effects, and there are still some controversy regarding the standardization that need to be clarified.

\section{References}

[1] Rhett, J.M., Ghatnekar, G.S., Palatinus, J.A., O’Quinn, M., Yost, M. J. and Reg, G. (2008) Novel Therapies for Scar Reduction and Regenerative Healing of Skin Wounds. Trends in Biotechnology, 26, 173-180. http://dx.doi.org/10.1016/j.tibtech.2007.12.007

[2] Cullum, N. (2001) Systematic Reviews of Wound Care Management: (5) Beds; (6) Compression; (7) Laser Therapy, Therapeutic Ultrasound, Electrotherapy and Electromagnetic Therapy. International Journal of Technology Assessment in Health Care, 5, 1-227.

[3] Coelho, M.B., de Souza, I.A., Freire, M.G., Marangoni, S., Antunes, E. and Macedo, M.L. (2006) Neutrophil Migration in Mice Induced by a Mannose-Binding Lectin Isolated from Annona coriacea Seeds. Toxicon, 48, 529-535. http://dx.doi.org/10.1016/j.toxicon.2006.07.001

[4] Branski, R.C., Rosen, C.A., Verdolini, K. and Hebda, P.A. (2005) Biochemical Markers Associated with Acute Vocal fold Wound Healing: A Rabbit Model. Journal of Voice, 19, 283-289.

http://dx.doi.org/10.1016/j.jvoice.2004.04.003

[5] Rocha Jr., A.M., Andrade, L.C.F., Oliveira, R.G., Aarestrup, F.M. and Farias, R.E. (2006) Modulation of Fibroblast Proliferation and Inflammatory Response by Low-Intensity Laser Therapy in Tissue Repair Process. Anais Brasileiros de Dermatologia, 81, 150-156.

[6] Woodruff, L.D., Bounkeo, J.M., Brannon, W.M., Dawes, K.S., Barham, C.D. and Waddell, D.L. (2004) The Efficacy of Laser Therapy in Wound Repair: A Meta-Analysis of the Literature. Photomedicine and Laser Surgery, 22, 241-247. http://dx.doi.org/10.1089/1549541041438623

[7] Reis, S.R.A., Medrado, A.P., Marchionni, A.M.T., Figueira, C., Fracassi, L.D. and Knop, L.A.H. (2008) Effect of 670nm Laser Therapy and Dexamethasone on Tissue Repair: A Histological and Ultrastructural Study. Photomedicine and Laser Surgery, 26, 307-313. http://dx.doi.org/10.1089/pho.2007.2151

[8] Mavver-Biscanin, M., Mravak-Stipetic, M. and Jerolimov, V. (2005) Effects of Low-Level Laser Therapy on Candida Albicans Growth in Patients with Denture Stomatitis. Photomedicine and Laser Surgery, 23, 328-332. http://dx.doi.org/10.1089/pho.2005.23.328

[9] Pardi, G. and Cardozo, E.I. (2002) Detection de especies de candida en pacientes con stomatitis sub-protésica. Acta Odontológica Venezolana, 40, 9-17.

[10] Wanessa, K.B., Giordano, C.G., Juliano, S.L., Fabiola, M.M., Silvana, M.S., Mariane, E. and Emerson, A.C. (2010) Use of ALGaInP Laser in the Wound Healing of Experimental Cutaneous Lesions in Rabbits. Acta Scientiae Veterinariae, 38, 237-243.

[11] Prata, M.B., Haddad, C.M., Goldenberg, S, de J. Simöes, M., de Moura, L.A.R. and Trabulsi, L.R. (1988) Uso tópico do açúcar em ferida cutânea. Estudo experimental em rato. Acta Cirurgica Brasileira, 3, 43-48.

[12] Ramsey, D.T., Papa, E.R., Mann, W.C., Berg, J.N. and Swaim, S.F. (1995) Effects of three occlusive dressing materials on healing of full-thickness skin wounds in dogs. American Journal of Veterinary Research, 56, 941-949.

[13] Pugliese, L.S., Medrado, A.P., Reis, S.R. and de Araújo Andrade, Z. (2003) The Influence of Low-Level Laser Therapy on Biomodulation of Collagen and Elastic Fibers. Pesquisa Odontológica Brasileira, 17, 307-313. http://dx.doi.org/10.1590/S1517-74912003000400003 
[14] Guirro, R.R.J. and Guirro, E.C.O. (2004) Analysis of the Transmissivity of Low Power Laser Radiation in Different Occlusive Dressings. 5th Congress of the World Association for Laser Therapy, Guarujá, 19.

[15] Gál, P., Vidinský, B., Toporcer, T., Mokrý, M., Mozes, S. and Longauer, F. (2006) Histological Assessment of the Effect of Laser Irradiation on Skin Wound Healing in Rats. Photomedicine and Laser Surgery, 24, 480-488. http://dx.doi.org/10.1089/pho.2006.24.480

[16] Cressoni, M.D.C., Giusti, H.H.K.D. and Casaroto, R.A. (2008) The Effects of a 785-nm AIGaInP Laser on the Regeneration of Rat Anterior Tibialis Muscle after Surgically-Induced Injury. Photomedicine and Laser Surgery, 26, 461466. http://dx.doi.org/10.1089/pho.2007.2150

[17] Zhang, X.J., Chinkes, D.L., Cox, R.A. and Wolfe, R.R. (2006) The Flow Phase of Wound Metabolism Is Characterized by Stimulated Protein Synthesis Rather Than Cell Proliferation. Journal of Surgical Research, 135, 61-67. http://dx.doi.org/10.1016/j.jss.2006.03.003

[18] Iunes, D.H., Ferreira, L.R. and Reis, N.S. (2005) Comparative Study on the Use of Therapeutic Ltrasound and Heliumneon Laser (He-Ne) for Treating Experimental Wounds in Wistar Rats. Investigação, 5, 50-57.

[19] Vincensi, C. and Carvalho, P.T.C. (2002) The Effects of the Laser Gallium Arsenide (AsGa) in Treatment of Inflammation in the Articulation in Wistar Rats through the Complete Adjuvant of Freund. Fisioterapia Brasil, 3, 223-230.

[20] Medrado, A.R., Pugliese, L.S. and Reis, S.R. (2003) Influence of Low-Level Laser Therapy on Wound Healing and Its Biologicalaction upon Myofibroblasts. Lasers in Surgery and Medicine, 32, 239-244. http://dx.doi.org/10.1002/lsm.10126

[21] Mello, P.B., Sampedro, R.M.F. and Piccinini, A.M. (2007) Effects of the He Ne Laser and of the Application Mode on Healing Burns in Rats. Fisiotererapia \& Pesquisa, 14, 6-13.

\author{
Abbreviations \\ postoperative (PO) \\ Laser (Light Amplification by Stimulated Emission of Radiation) \\ AlGaInP (Aluminium, Gallium, Indium, Phosphorus) \\ HeNe (Helium Neon) \\ Control of Animal Experimentation (CONCEA) \\ Committee on the Use of Animals (CEUA) \\ University of Fortaleza (UNIFOR) \\ Wo $=$ initial wound area \\ $\mathrm{Wi}=$ final wound area
}

